\title{
Erratum to: CT of inferior vena cava filters: normal presentations and potential complications
}

\author{
Nicholas A. Georgiou ${ }^{1}$ - Douglas S. Katz ${ }^{1} \cdot$ George Ganson $^{2} \cdot$ Kaitlin Eng $^{3} \cdot$ Man Hon $^{1}$
}

Published online: 20 August 2015

(C) American Society of Emergency Radiology 2015

Erratum to: Emerg Radiol

DOI 10.1007/s10140-015-1333-6

The original version of this article, unfortunately, contained an error.

The image of Figure $4 \mathrm{~b}$ was incorrect. The correct image is given in this article.

The online version of the original article can be found at http://dx.doi.org/ 10.1007/s10140-015-1333-6.

Nicholas A. Georgiou

Georgiou.Nicholas@Gmail.com

1 Department of Radiology, Winthrop-University Hospital, 259 First Street, Mineola, NY 11501, USA

2 Department of Radiology, Point Pleasant Radiology Group, Ocean Medical Center, 425 Jack Martin Boulevard, Brick, NJ 08724, USA

3 Department of Radiology, Yale-New Haven Medical Center, 20 York Street, New Haven, CT 06510, USA 